\title{
Exploring Point of Sale Strategies for Improving Seafood Retailing: The Case of the Australian Oyster Industry
}

\author{
Meredith Lawley ${ }^{1}$ and Dawn Birch ${ }^{2}$
}

\footnotetext{
${ }^{1}$ Professor, School of Business, University of the Sunshine Coast, Sippy Downs Drive, Maroochydore DC, Qld, 4558, Australia

$\bowtie$ mlawley1@usc.edu.au
}

${ }^{2}$ Senior Lecturer, The Business School, Bournemouth University, Executive Business Centre, United Kingdom, BH8 8EB. 


\begin{abstract}
The commodification of many food products, combined with increasing market share of supermarkets, has increased the importance of point of sale (POS) strategies in speciality food retailers such as fishmongers. The purpose of this study is to develop strategies to improve the retailing of seafood in fishmongers, specifically oysters, a species which is currently underutilised; as although they are eaten by many consumers, purchase frequency is low. A literature review identifies the key drivers and barriers to oyster consumption and the information consumers want at the POS. Based on these findings, a retailing strategy for oysters is developed and tested in two consumer focus groups. Based on focus group results, revisions are recommended to the retail strategy, importantly including a change in collateral from a production focus to a consumption focus. This study makes a clear contribution to theory and practice by bringing together the existing literature on drivers and barriers and consumer information requirements about oysters to develop and test practical retail strategy concepts.
\end{abstract}

Key words: seafood; retailing; point of sale (POS)

\title{
Introduction
}

Agribusinesses in Australia have traditionally been production-driven as opposed to marketdriven, with producers selling seasonal products as commodities based on price with little differentiation across product offerings (Bonney et al., 2007). The Australian seafood industry is no exception, as it is largely supply rather than demand-driven. This is evident through simply off-loading what is caught or farmed and taking the best possible price, with little consideration of consumer demand and possibilities for price-making. In more recent times, other agri-food industries in Australia (e.g. meat, livestock and dairy industries) have recognised the potential for growing market share through a more targeted marketingoriented approach. For example, several industry-based marketing campaigns have encouraged Australians to eat more Australian lamb ('We Love our Lamb'), while the Australian beef industry has asked Australians to 'Throw Another Steak on the Barbie', and the Australian pork industry has encouraged consumers to 'Get Some Pork on Your Fork'. These industry level campaigns have been complemented at the retail level with point of sale (POS) materials such as posters, stickers and recipe cards. 
To better compete with supermarkets, many specialty food retailers (butchers, bakers, greengrocers etc.) have adopted a scrambled merchandising approach through value-added products (e.g. pre-prepared ready-to-eat options, individual servings, etc.), product lineextensions (e.g. organic and gluten-free ranges) and have supplemented their basic food offering with a variety of additional accompaniments (e.g. sauces, marinades, toppings, etc.); as well as associated merchandise such as recipe books, aprons and cooking implements. Speciality food retailers are becoming increasingly aware of consumers' growing needs and interest in product information such as where, when, and how products have been grown/produced (i.e. provenance and traceability), nutritional information, and preparation and serving suggestions. While some Australian fishmongers have developed their retailing concept with value-added products, accompaniments, and the occasional recipe card, more could be done to improve the seafood retailing experience and offering. In the oyster category, for example, the retail offering has remained unchanged, with oysters typically sold in half shell format in half or one-dozen packs and presented with very little consumer information. Provenance information is scarce, and in some cases may be misrepresented at the POS. The challenge for the seafood industry is to increase consumption through improved marketing and retailing. In particular, this is critical for species that are underutilised either because they are less popular (e.g. sardines) or popular but less frequently consumed such as oysters (Danenberg \& Mueller, 2011).

Oyster production in Australia expanded from around 10,200 tonnes in 2001 to 12,530 tonnes in 2012, accounting for a market value of around \$A94.5 million (ABARES, 2014), with the three main species of oysters cultivated in Australia being the Sydney Rock oyster, the Pacific oyster and the Angasi (Liu et al., 2006). Australian consumption of oysters is limited, despite substantial nutritional and health benefits and oysters being ranked as the eighth most popular seafood species in Australia. Indeed, research has also revealed that while $60 \%$ of Australians like oysters, only 37\% consume them on a regular basis (Danenberg \& Mueller, 2011). In light of recent consumer research, the Australian oyster industry has become increasingly interested in and supportive of initiatives that can be shown to increase sales and/or grow margins. Research has revealed opportunities to increase sales through improved merchandising and information at point-of-sale (POS) (Fitzgerald \& Lawley, 2013). The industry has recognised the need to more fully understand consumers' preferences, consumption patterns and attitudes towards oysters in order to maintain prices and maximise 
economic returns. In particular, the need to educate consumers about oysters; where they come from, different varieties, styles and flavours and the nutritional benefits.

While improvements in marketing and retailing and a shift away from a supply-driven production toward demand-driven marketing approach are required across the seafood sector, this paper focuses specifically on the case of Australian oysters. The research question addressed in this paper is: What point of sale (POS) strategies would increase consumption of oysters? Key research objectives include: exploring the barriers and drivers of oyster consumption in Australia; determining what information consumers need at the point of sale, and identifying retailing formats/strategies that would appeal and encourage oyster consumption.

\section{Background}

Previous studies of oyster consumption have revealed that consumers are interested in the health benefits of oysters. Oysters are typically consumed at restaurants rather than at home, and there is a strong preference for open oysters in the half shell (Hardesty, 2001). Price, product safety and availability have been found to drive consumption of oysters, while dislike of the taste, texture, and smell of oysters have been identified as key barriers (Hanson et al., 2003). The need for a greater understanding of factors influencing oyster consumption in Australia and limited research on consumer choice criteria for oysters has led to increased research in recent times (Danenberg \& Mueller, 2011; Danenberg \& Remaud, 2010; Kow et al., 2008; Liu et al., 2006; Loose et al., 2013).

A national study of 696 Australian consumers (including 468 oyster eaters) conducted by Liu et al. (2006), and later reported by Kow et al. (2008), investigated 24 physical and intangible attributes of oysters (e.g. taste, freshness, knowledge of preparation and price). Key factors influencing oyster consumption in Australia include quality (e.g. taste and freshness), safety, labelling, and preferred values such as seasonality, variety, price, packaging, etc. (Liu et al., 2006). In particular, correct labelling was deemed important - including where and when the oyster was caught or farmed, and species type and information regarding fresh versus frozen or defrosted. Issues related to safety were also found to be important, including quality assurances and environmental concerns. The majority (71\%) of respondents indicated a preference for fresh oysters in the half shell, with preferred purchase locations being 
restaurants (37\%) and specialty fishmongers (24\%). This preference for half shell oysters was interpreted as the need for the consumer to have greater control over the purchasing situation by being able to more easily assess the oyster for freshness and quality, and thus Kow et al. (2008) proposed that greater quality management within the supply chain was essential. Moreover, Kow et al. (2008) suggested that preference for consuming oysters at restaurants may indicate that consumers are not comfortable with selecting and preparing oysters at home, due to lack of knowledge and safety concerns. Based on concerns regarding safety, labelling and given that about $20 \%$ of respondents indicate a preference for Kilpatrick style oysters, Kow et al. (2008) suggested opportunities for better marketing, branding, and labelling of oysters; as well as product development. Likewise, Liu et al. (2006) identified the importance of appealing to younger people and the need for serving suggestions or recipes. Liu et al. (2006, p. 92) also argued that consumers need information on where oysters are grown and differences across species, calling for brochures outlining 'growing regions, growing methods, handling procedures, storage knowledge, nutritional benefits (i.e. lower cholesterol than other shellfish), quick and easy recipes and flavour profiles' as well as seasonal information. Other marketing activities suggested by Liu et al. (2006) included creating interesting retail marketing experiences such as exhibiting oysters at the point of sale (e.g. 'oyster of the day').

A national study of Australian seafood consumers $(n=1718)$ conducted in 2009 used discrete choice experiments to investigate the importance of various product packaging formats and convenient preparation in influencing consumer choice for oysters, relative to traditional demand factors such as 'price, region of origin, oyster species, health, environmental and quality claims' (Loose et al., 2013, p. 492). The discrete choice experiments presented consumers with pictures of successive sets of alternative offerings and aimed to simulate the consumer choice situation for ready-packaged oysters at the point of sale. The study revealed that price (28\%); preparation format (26\%) and species (25\%) mostly influenced choice, while region of origin (14\%) and accompaniments/serving suggestions (4\%) also had some impact on choice. However, with respect to accompaniments, the impact was only positive for familiar accompaniments (i.e. for Oysters Kilpatrick rather than Champagne Sabayon). Moreover, tray packaging (2\%), marketing claims which include health ticks and carbon zero claims (1\%), and gold medal claims (less than 1\%) had very minimal influence on choice between competing offerings of oysters (Birch, 2012). The identification of consumer segments based on preferences suggested opportunities for 'consumer-oriented product 
Exploring Point of Sale Strategies for Improving Seafood Retailing: The Case of the Australian Oyster Industry

differentiation with the potential to increase oyster demand and healthy seafood consumption’ (Loose et al., 2013, p. 492).

Lower levels of seafood consumption are associated with numerous barriers - including price (Brunsø et al., 2009; Olsen, 2004; Verbeke \& Vackier, 2005), lack of perceived availability, consumers' lack of knowledge and confidence to evaluate the quality and freshness of seafood (Pieniak et al., 2008), as well as perceived inconvenience of seafood as a meal option, including being too time-consuming and difficult to prepare (Altintzoglou et al., 2010; Olsen et al., 2007; Rortveit \& Olsen, 2009). Lack of perceived convenience in food preparation is becoming increasingly important due to a stronger convenience orientation among time-poor consumers (Brunner et al., 2010; Mahon et al., 2006; Olsen et al., 2012). Oysters are of particular concern, as many consumers find it difficult to assess their freshness and quality as they are more associated with perceptions of being difficult to prepare and store (i.e. shucking, limited shelf-life). Indeed, Australian consumers express preference for pre-opened oysters that do not require shucking. Moreover, oysters are linked with greater safety concerns than many other seafoods. These barriers may be addressed through more effective retailing and packaging, thus providing greater convenience and assurance for consumers with respect to preparation and storage (Loose et al., 2013).

A perceptual study comparing differences across popular seafood species, conducted by Danenberg and Remaud (2010), revealed that oysters are less mentally available and associated with many weaknesses as compared with other seafood species (e.g. prawns, barramundi and basa). Loose et al. (2013) concur that potential meal usages for oysters are perceived as limited by consumers. For example, while oysters are considered to be natural and healthy, they are not considered to be always safe to eat. Compared to many other seafood species, oysters are considered to be less versatile or easy to prepare, deemed to have a short shelf-life and not suitable for freezing, and thus needing to be eaten immediately after purchase. Moreover, oysters are not considered to be widely available, with availability being limited to fishmongers and are rarely stocked in supermarkets (Loose et al., 2013). Moreover, in line with European studies, oysters are considered to be rather expensive and not good value, and thus considered to be a luxury food more suited to special occasions or when dining out rather than for everyday meals (Girard \& Mariojouls, 2003). 
In terms of current practice, Australian oysters sold through specialty seafood retailers are typically packaged in pre-moulded black PET trays. Limited information is provided at the point of sale in terms of species, region, nutritional information or use-by-dates.

\section{The Retailing Concept}

Based on the consumer research regarding drivers and barriers to oyster consumption, the Australian oyster industry proposed a strategy to improve the retailing of oysters in fishmongers. In line with research that indicated consumers lacked confidence in selecting, preparing and serving oysters and desired more information on different species and origin, the Australian oyster industry set about developing a concept (which at the time was called the 'Oyster Shed') which comprised a black plastic presentation tray to house oysters of different varieties on ice and in individual beds in three different formats: unopened live, half shell and easy-open. The presentation trays were designed to fit easily into fishmongers' existing retail display cabinets. The prototype module had a shelf-talker attached to the front which provided information on species, region (depicted by a dot on the Australian map), and tasting notes similar to those most typically associated with wine. The tasting notes were based on the sensory characteristics of various species of oysters. For example, 'A firm oyster with a burst of salty, sweet ocean and slight herbaceous flavour'.

Accompanying the module at the point of sale, a range of marketing collateral was proposed including a poster and brochure (to be displayed above the oyster cabinet). Proposed imagery for the poster and brochure revolved around an oyster farmer eating a plate of natural oysters with lemon with the quote:

'Eating an oyster is like taking that first plunge into the ocean, it's clean, pristine, fresh....taste the brine first, then the textures and flavours'.

Behind the oyster farmer was the picture of an oyster shed where oysters are grown in pristine blue waters. The Oysters Australia logo (three concentric oval shapes depicting an oyster) and a proposed tagline: 'Fresh Australian oysters, everyday luxury', as well as information on handling oysters and a serving suggestion were also displayed on the poster.

The proposed information brochure provided information on varieties, growing/harvesting regions, how to buy, store and prepare oysters, as well as a recipe. Other marketing ideas 
included the provision of accompanying sauces and recipe cards at the point of sale. In addition, it was proposed that an oyster shucker would be positioned at the front of the store at some outlets to demonstrate the shucking technique and encourage shoppers to try the oysters, thus creating a unique in-store experience.

\section{Methods and Materials}

As the initial concept development was based on existing consumer research, to test the oyster retailing concepts, two-45 minute focus groups $(\mathrm{n}=15)$ were conducted. Participants were recruited by convenience and snowballing to identify consumers who have purchased oysters from a fishmonger in the past 12 months. With the permission of participants, the discussions were recorded and transcribed. Thematic analysis was undertaken to identify recurring themes and to address the research questions and objectives.

The focus groups comprised 9 males and 6 females with 4 participants under 50 years of age (25 - 49) and 11 being 50 years or older. All participants resided in South East Queensland, Australia. No further demographic data was collected. All participants had consumed oysters in the past 12 months, with 6 participants consuming oysters about once per month and 9 consuming oysters about every 2-6 months. In brief, the profile of participants was skewed to older and more frequent oyster consumers.

\section{Results}

Before addressing the specific research objectives, participants were asked some general warm up questions about their oyster purchasing behaviour, including where they typically purchase oysters. Most of the participants prefer to purchase oysters from a reputable or trusted outlet such as a local fishmonger. One participant commented:

'I think it's really important that you're buying them from a fishmonger who you can trust, so therefore whatever is on that shelf you know you can buy it and trust it'.

Others agreed, stating:

'Reputation is most important, especially with seafood'.

Many expressed negative attitudes toward purchasing oysters at supermarkets due to perceived low quality, poor displays, and not receiving the right information regarding freshness: 
Exploring Point of Sale Strategies for Improving Seafood Retailing: The Case of the Australian Oyster Industry

'If you ask behind the counter at Safeway, they can't tell you or won't tell you'.

However, one participant who purchased from supermarkets stated:

'I haven’t had a bad experience yet'.

Some participants pointed out that they only purchase oysters when eating out:

'Only at a restaurant, I don't know - it puts me off somehow at a retailer, I just don't know why. I can’t explain it, but I never really buy them unless we're out for dinner'.

In terms of how oysters are consumed, most prefer to eat oysters raw (natural) with lemon, with a couple of the participants also liking Oysters Kilpatrick.

Next, consumers were asked about what would make them buy oysters more often. Responses included in-store factors (e.g. taste testing in stores, shucking at the point of sale, better displays). One participant stated:

'If they were shucking them in front of me on a bed of rock salt or ice or something I'd be much more interested; but these black plastic trays with cellophane to me is a real turn-off'.

Greater availability (proximity to the seafood outlet, access to trusted and reputable restaurants or outlets and greater variety were also highlighted, as were preferred regions:

'I’d eat them every day if I could; we buy Coffin Bay oysters'.

Moreover, better knowledge (different species, origins and locality, nutritional information, spawning season), price and quality issues (affordability, good price and quality, good appearance, freshness), were key drivers for purchasing more oysters, as was acceptability:

'Nobody else in my family eats them'.

And safety:

'I don’t know how long they last'.

'I've got to eat it that night'.

'We sometimes keep the prawns until the next day but we never go that far with the oysters'.

One participant explained: 
'If I had knowledge of how long they had been opened and how long they last after they're opened then I might buy them more often to eat them a couple of days later'.

Another elaborated:

'Mainly it's a labelling problem with what is meant by fresh; so if they could maybe put the date they were caught or opened on the packet so that you know how long it's been and if what you bought that day had just been opened'.

Two of the participants, one from Europe and one who was involved in the seafood industry, noted that the availability of live oysters would encourage them to purchase more oysters; however, all other participants strongly rejected the idea that consumers would want to know that the oysters are alive.

A couple of participants noted that they did not consider oysters to be a main meal, but rather an occasional treat or luxury or something they eat on random occasions with friends and thus, they would not consume oysters more often, with one participant explaining:

'I would need to change my mindset; I only think of them for special occasions'.

Another participant explained she does not eat oysters more frequently because they are 'outrageously expensive'. Conversely, another respondent, while acknowledging oysters to be a bit expensive, stated:

'I think they're pretty cheap really for the joy they give me'.

Indeed, oyster consumption appears to be associated with hedonistic pleasure. For example, one participant explained:

'I buy them to gratify myself because it's one of the things that make me think of my childhood and I'm very ready to gratify myself straight away, so I'll go for it as soon as I get home... they don't ever get in the fridge. I put them on a plate, I put ice or salt on to make them look pretty because I like it like that and I have to have a very sharp white wine'.

However, this pleasure appears to be mixed with some level of guilt, with oysters being deemed to be an expensive treat or indulgence. Participants commented:

'I don't spoil myself, it is an unnecessary spend'.

'They are not a staple...to be enjoyed in moderation'. 
'The price has to be reasonable when compared to other seafood, otherwise I would still consider them a luxury - I need to not feel guilty when I buy them’.

In addition to price, lack of physical availability of a good quality product appears to be a major barrier to increased consumption, with most respondents raising this obstacle. Moreover, when oysters are available, they are typically:

'...poorly displayed and presented and don’t look fresh'.

Lack of mental availability was also evident, with respondents commenting:

'Not sure how long I can keep them'.

All participants perceived the need to eat them the same day, one stating:

'I could not eat them the next day, so I think that's lack of knowledge'.

These concerns led two of the participants only to consume oysters when dining at a reputable, trustworthy restaurant.

\section{Concept Testing}

Participants were shown photographs of the proposed concepts for oyster retailing and asked their opinion about whether they would impact on their purchase decisions in-store and why. First, they were shown the drawing of the presentation tray (see Figure 1) and explained the concept regarding different varieties, formats, tasting notes, regional information, and suggested concept names (Oyster Bar or Oyster Shed). Overall, participants were impressed with the concept, considered it to be interesting and that it would encourage them to buy more oysters; one stating:

'It looks like it’s done properly rather than the shoddily way it’s done with a bit of cling wrap'.

They appreciated the educational value behind the concept:

'Why not educate me while I'm standing there, although it wouldn't be hard to go past it, but educate me; there might be something else that I can try and enjoy’.

One stated:

'Choice is always a good idea'. 
In particular, they valued the idea of being provided with provenance and local information; however, they wanted more regional information (maps with dots to indicate regions) and information regarding harvesting and shucking dates, as well as how to store the oysters and for how long. One participant preferred that minimal handling was best, while most did not like the use of plastic food wrap. Most participants liked the black trays, but others preferred white or lemon. Negative comments included:

'Too much writing on the signs'.

'It looks dry... it needs to be packed in ice'.

A couple of participants indicated a preference for a more natural presentation which showcases the oysters in their environment of water and rocks rather than in plastic trays. This would be in line with how oysters are retailed in the supermarkets in New Zealand, stating that the products being displayed were in:

'facsimiles of out on rocks with waterfalls... in a way that you just want to be part of it and take it home'.

Suggestions for improving the concept included availability of sampler packs (a mix of oyster varieties), and provision of a tray with a fork for eating as a take-away. While the majority of participants liked the presentation tray concept, two participants thought it was boring and suggested a more exciting approach to displaying the oysters.

In terms of the concept name, participants preferred 'Oyster Bar' over 'Oyster Shed', but were not enthused with either, with most not perceiving the need for naming the concept at all. Other suggestions included 'Wild Oysters', 'Oyster Pool' and 'Oyster Rock':

'Because that is where oysters come from, apart from the farmed ones, they grow on rocks'.

Participants were asked if a person shucking oysters in-store would encourage them to purchase oysters. Generally, participants thought this would be a great idea, and that fresh shucked oysters would definitely encourage them to buy. In particular, they considered it would be useful if the shucker provided information on how to easily shuck oysters and how to store them. One enthused participant stated:

'I think that definitely I'd be more encouraged to see someone shucking the oysters fresh in front of you and being able to buy them that way. Absolutely, without a doubt'. 
However, others questioned the cost versus benefits of such a strategy. Participants also believed that being able to sample oysters would encourage people to try and buy, and thus would add to the overall consumption experience.

Participants were shown a prototype of a top of counter sauce display and asked if accompanying sauces above the oyster presentation trays would be appealing. There was little interest among participants regarding accompanying sauces as they primarily consume oysters raw with just lemon. Indeed, one participant suggested that:

'A bowl of lemons on the counter would be more appealing'.

One participant felt that rather than adding value, that the accompanying sauces and all these other things took away from the oyster experience. However, some participants agreed that it may encourage younger people or:

'...people who don't know [how to prepare and serve oysters] and they think, "oh maybe I'll try it with that"'.

Participants were also asked if recipe cards and serving suggestions at the point of sale would encourage people to purchase oysters. There was little personal interest in recipes and serving suggestions among the focus group participants. Most participants were not convinced these would work, but noted that they could be:

'...of some interest to those who don’t know how to cook oysters'.

It was also noted that recipe cards and serving suggestions may encourage non-eaters.

Having discussed the retail presentation trays, the discussion turned to branding issues. First, participants were asked their opinions of a range of potential taglines/slogans generated on the basis of the consumer research including:

- 'Everyday luxury'

- 'Taste of the sea'

- 'Enjoy, the taste of the sea'

- 'Everyday treats from the sea'

- 'Go on, spoil yourself'

- 'Indulge your senses'

- 'Experience the taste of the sea everyday'

- 'Enjoy, everyday' 
Acknowledging that people like to 'indulge even if we don't have money', one participant suggested the tagline, 'Affordable luxury'. However, as a rule, the words 'luxury', 'indulge' and 'spoil', and to a lesser extent 'treat', were rejected by most participants as they evoked feelings of guilt and served to reinforce the notion that oysters are expensive and only for special occasions. One participant summed up the group sentiment with the following comment:

\begin{abstract}
'If you're trying to market it to more people, I'd get rid of luxury and indulgence because to me that says money. I'd be sort of saying 'Oysters everyday', you know, bring it down to something that is more commonplace'.
\end{abstract}

Other participants stressed the need for the use of the words 'fresh' or 'natural' in the tagline and the need to keep it simple. One participant who favoured a tagline that captured the natural characteristics of the oyster stated:

'This is something that is natural. It's like eating strawberries or fruit, nothing's been done to an oyster, you're just eating it as it is, and I think that is such a good marketing tool because you know people are looking to be healthy and not have processed food'.

Ideas around this theme included 'Naturally delicious' or 'Natural indulgence'. Other ideas arising from the taste of oysters included 'Experience the taste' and 'Experience the taste of the sea everyday'.

After considerable discussion, participants in the first focus group agreed that 'Fresh Australian oysters, enjoy everyday' captured consumers' desire for fresh oysters of an Australian origin, highlighted the idea that oysters could be enjoyed on an everyday basis, and stressed the enjoyment to be gained from eating oysters. The second group was more divided in their opinions, but agreed that the tagline ‘Enjoy everyday’ could work.

Next, participants were shown the proposed poster to be used at the point of sale (refer to Figure 2). Participants generally did not like the proposed poster, considering it to be too cluttered with too much going on and too many messages. They also commented on the need to keep it simple with a focus on keeping the enjoyment message going. In particular, they rejected the imagery with key concerns around the fisherman being too old. Indeed, if a fisherman was to be used they would prefer:

‘...a younger burlier person to appeal to females'. 
Indeed, most participants knew about the touted aphrodisiac qualities of oysters, with one proposing that eating oysters is:

'....almost a romantic type of thing, because it does have a name as an aphrodisiac in historical terms and it's something you enjoy with a glass of wine'.

They stressed the need to appeal to a whole new generation of hedonistic Australian oyster eaters by depicting:

'...casually dressed younger and sophisticated consumers loving them, enjoying them, scoffing them and relishing the oyster'.

Another agreed:

'...having young people loving and obviously enjoying the oyster experience'.

They also suggested depicting the oysters being consumed with beer and white wine as opposed to the traditional champagne as a means to:

'...take the elitist out of it so that it's not a luxury item, so that they're marketing it to the everyday person'.

Participants indicated a preference for a series of posters depicting young people eating and enjoying oysters across a range of everyday consumption occasions (e.g. parties, BBQs or at the beach).

The quote was considered to be 'too long' and that 'nobody would read it'. Rather, they argued that an amusing or quirky quote that plays on and incorporates 'the funny thing about the aphrodisiac stuff' would be more effective. One participant pointed out:

'...if you've got it [a known selling point such as aphrodisiac qualities] why not use that advantage to save you creating another one’.

The oyster shed imagery was not well understood and raised negative comments about farmed oysters, with one participant explaining to the group that $99.9 \%$ of oysters are farmed, eliciting the response:

'Well, being a romantic, I'd like the real thing and go back to where they used to be'. 
Exploring Point of Sale Strategies for Improving Seafood Retailing: The Case of the Australian Oyster Industry

Another participant argued:

'I don’t think anybody really wants to know they’ve been raised on a farm, people aren’t interested'.

The supply-side, production oriented approach was not considered effective:

'Only people who are in the industry, the oyster industry, realise that the shed is all about oysters. To a normal consumer it's just an old shed on the end of a pier and what's that got to do with oysters?'.

Rather, demand-side, market driven imagery depicting consumption occasions was deemed to be more compelling.

Participants liked the bowl of fresh oysters with lemon in the foreground, as this depicted how most people consume oysters. However, the serving suggestion was deemed unnecessary and other elements such as the red oysters plank was also considered to be superfluous and only added to the clutter. The handling information regarding knowing how long opened oysters can be kept in the fridge was deemed useful, however it was considered to be presented in too small a font to read in-store. Only two of the participants were interested in the information regarding unopened oysters being live and suggested this would appeal to certain markets such as the Asian and European markets. However, the remainder of the participants definitely did not want to know that the oysters in the store were still alive. One participant captured the common belief that people:

'... want to know it's fresh, but they probably don't want to know that it's live, if you tell them it’s live they’ll probably [think] “ooohhh... it might start wriggling”'.

Participants were asked about what sorts of consumer education/information was needed and whether a sticker on take-home packages would be useful. Participants wanted information on how to store oysters. Participants considered that a sticker with information on how to store oysters, harvest and use-by-dates, as well as place of harvest would be useful. Participants favoured the idea of placing an Australian map with dots indicating where oysters are grown. Only one participant was interested in nutritional information, while very few were interested in recipes or serving suggestions.

Finally, participants were asked which of the retailing and branding strategies they had been presented with would be most effective in terms of increasing oyster purchases. Participants 
considered the presentation trays with the shelf-talker would be most effective, followed by the in-store shucker and then opportunities for sampling.

\section{Discussion and Implications}

The focus group discussions were valuable for validating previous consumer research on oyster consumption and consumers' attitudes toward oysters in Australia, and also for testing and identifying strategies for increasing oyster consumption through more effective retailing strategies. The research demonstrates the importance of underpinning retailing activities with a strong understanding of consumers' preferences, attitudes and behaviour. In particular, this research highlighted the importance of taking a marketing-oriented, demand-based approach as opposed to an industry production-oriented, supply-based approach to branding strategies. Based on the findings of the focus groups, the proposed retailing concept was refined and reworked to focus more on consumption occasions, as opposed to production methods (as outlined next).

First, based on positive reactions to the retailing concept, plans for further development of the concept were put in place. Such plans include the production of black presentation trays with beds to allow half shell fresh Australian oysters (of a range of varieties) to be individually showcased in fishmongers' display cabinets, along with associated light blue shelf-talkers attached to the front of the trays to focus on desirable features and qualities such as variety (e.g. Pacific oyster), region (Australian map with a dot indicating place of harvest), and sensory tasting notes (e.g. 'A firm oyster with a burst of salty, sweet ocean and slight herbaceous flavour') .

Moreover, based on previous research and the information gleaned from the focus groups, point of sale brochures (which would sit in clear plastic holders on the display cabinet above the oysters) were planned. The brochures will provide important product information on oyster varieties, growing regions, and how to buy, store and serve oysters (including how to shuck unopened oysters). Further, a blue sticker (that would be attached to wrapped products for taking home) was planned to include a map showing the region where the oysters were harvested and information such as use-by-dates and storage information. The focus group discussions indicated that an in-store shucker and product sampling would be effective in terms of generating interest, creating a more dynamic retailing experience and encouraging 
trial and purchase; thus negotiations were put in place with a merchandising company to recruit appropriate staff and develop the necessary merchandising unit for the in-store shucking and tasting activity.

A revised poster was conceived on the basis of focus group discussions to include the established Oysters Australia logo accompanied by the tagline 'Fresh Australian oysters, enjoy everyday'. The posters depict young people enjoying oysters in a casual consumption occasion (beside a pool in a coastal location) to focus on the hedonic pleasure and enjoyment of oyster consumption. The oysters are served au naturel and 'star' at the forefront of the poster. Like many other pre-prepared seafood products, pre-shucked oysters served au naturel with a slice of lemon actually represent an easy to prepare and healthy ready-to-eat meal (Olsen et al., 2012).

\section{Conclusions}

This study had three key objectives. The first objective of exploring the barriers and drivers of oyster consumption in Australia was well covered in the existing literature, with the focus group results supporting the key findings and adding further depth and understanding of these barriers and drivers. In terms of the second objective of determining what information consumers need at point of sale, again this study supported findings of the extant literature. The most important findings from this study lie with the third objective, identifying retailing strategies that would appeal and encourage oyster consumption. Having understood barriers and drivers and identified the required information, this study tested and explored how the required information should best be presented at point of sale to be effective in driving purchase. This is an area which had not been explored previously. As a result, several revisions were made to the retailing concept as originally planned (by industry/producers) to ensure a strong consumer focus.

Based on the revised strategies, the next step will be to trial the POS strategies in the field. Questions still remain regarding which POS materials will have the most impact, how practical each piece of collateral will be in different retail settings, and what impact in-store sampling will have. 
Exploring Point of Sale Strategies for Improving Seafood Retailing: The Case of the Australian Oyster Industry

\section{List of References}

ABARES. (2014). Australian fisheries and aquaculture statistics 2013. Australian Bureau of Agricultural and Resource Economics and Sciences.

Altintzoglou, T., Birch-Hansen, K., Valsdóttir, T., Odland, J. Ø., Martinsdóttir, E., Brunsø, K., \& Luten, J. (2010). Translating barriers into potential improvements: The case of new healthy seafood product development. Journal of Consumer Marketing, 27(3), 224-235. doi: $10.1108 / 07363761011038293$

Birch, D. (2012). Tracking seafood consumption and measuring consumer acceptance of innovation in the Australian seafood industry. Australian Seafood Cooperative Research Centre, the UniSA Ehrenberg-Bass Institute for Marketing Science, and the University of the Sunshine Coast.

Bonney, L., Clark, R., Collins, R., \& Fearne, A. (2007). From serendipity to sustainable competitive advantage: Insights from Houston’s Farm and their journey of co-innovation. Supply Chain Management, 12(6), 395-399. doi: 10.1108/13598540710826326

Brunner, T. A., van der Horst, K., \& Siegrist, M. (2010). Convenience food products. Drivers for consumption. Appetite, 55(3), 498-506. doi: 10.1016/j.appet.2010.08.017

Brunsø, K., Verbeke, W. Olsen, S. O., \& Jeppesen, L. F. (2009). Motives, barriers and quality evaluation in fish consumption situations: Exploring and comparing heavy and light users in Spain and Belgium. British Food Journal, 111(7), 699-716. doi: 10.1108/00070700910972387

Danenberg, N., \& Remaud, H. (2010). Omnibus consumer research findings. Australian Seafood Cooperative Research Centre and the UniSA Ehrenberg-Bass Institute for Marketing Science. 
Exploring Point of Sale Strategies for Improving Seafood Retailing: The Case of the Australian Oyster Industry

Danenberg, N., \& Mueller, S. (2011). Omnibus consumer research findings - Wave 2.

Australian Seafood Cooperative Research Centre and the UniSA Ehrenberg-Bass Institute for Marketing Science.

Fitzgerald, L., \& Lawley, M. (2013). Evaluating the impact of an improved retailing concept for oysters in fishmongers. Unpublished research project, Sippy Downs: University of the Sunshine Coast.

Girard, S., \& Mariojouls, C. (2003). French consumption of oysters and mussels analysed within the European market. Aquaculture Economics \& Management, 7(5-6), 319-333. doi: http://dx.doi.org/10.1080/13657300309380348

Hanson, T., House, L., Sureshwaran, S., Posadas B., \& Liu, A. (2003). Opinions of U.S. consumers toward oysters: Results of a 2000-2001 survey. Washington DC: US Department of Agricultural Economics.

Hardesty, S. (2001). Marketing opportunities for Pacific Coast oysters. Food Marketing \& Economics Group and Pacific Coast Shellfish Growers Association, California.

Kow, F., Yu, L., Fitzgerald, D., \& Grewal, D. (2008). Understanding the factors related to the consumers' choices of oysters in Australia: an empirical study. Journal of Foodservice, 19(4), 245-253. doi:10.1111/j.1748-0159.2008.00112.x

Liu, Y., Kow, F., Grewal, D., \& FitzGerald, D. (2006). Consumer purchase behaviour for oysters: an empirical study in some state capital cities of Australia. International Journal of Consumer Studies, 30(1), 85-94. doi: 10.1111/j.1470-6431.2005.00456.x

Loose, S. M., Peschel, A., \& Grebitus, C. (2013). Quantifying effects of convenience and product packaging on consumer preferences and market share of seafood products: The case of oysters. Food Quality and Preference, 28(2), 492-504. doi:

10.1016/j.foodqual.2012.11.004

Mahon, D., Cowan, C., \& McCarthy, M. (2006). The role of attitudes, subjective norm, perceived control and habit in the consumption of ready meals and takeaways in Great Britain. Food Quality and Preference, 17(6), 474-481. doi: 10.1016/j.foodqual.2005.06.001 
Exploring Point of Sale Strategies for Improving Seafood Retailing: The Case of the Australian Oyster Industry

Olsen, N. V., Menichelli, E., Sørheim, O., \& Næs, T. (2012). Likelihood of buying healthy convenience food: An at-home testing procedure for ready-to-heat meals. Food Quality and Preference, 24(1), 171-178. doi: 10.1016/j.foodqual.2011.11.001

Olsen, S. V., Scholderer, J., Brunsø, K., \& Verbeke, W. (2007). Exploring the relationship between convenience and fish consumption: A cross-cultural study. Appetite, 49(1), 84-91. doi: 10.1016/j.appet.2006.12.002

Olsen, S. V. (2004). Antecedents of seafood consumption behaviour. Journal of Aquatic Food Product Technology, 13(3), 79-91. doi: 10.1300/J030v13n03_08

Pieniak, Z., Verbeke, W., Scholderer, J., Brunsø, K., \& Olsen, S. O. (2008). Impact of consumers' health beliefs, health involvement and risk perception on fish consumption: A study in five European countries. British Food Journal, 110(9), 898-915. doi:

$10.1108 / 00070700810900602$

Rortveit, A.W., \& Olsen, S. O. (2009). Combining the role of convenience and consideration set size in explaining fish consumption in Norway. Appetite, 52(2), 313-317. doi:

10.1016/j.appet.2008.11.001

Verbeke, W., \& Vackier, I. (2005). Individual determinants of fish consumption: Application of the theory of planned behaviour. Appetite, 44, 67-82. doi: doi:10.1016/j.appet.2004.08.006 